\title{
Pensar en imágenes. Montaje y tensiones en el arte contemporáneo
}

\author{
Paula La Rocca \\ Universidad Nacional de Córdoba - Argentina
}

\begin{abstract}
Resumo
Perguntar-nos pelo presente objetivando o tempo em um corte que coincide com nós mesmos resulta quase irrealizável. Somente podemos confiar em vislumbrar certas fendas ou passagens que fraturam o próprio presente para, a partir daí, arriscar algum tipo de articulação. Pensar em imagens como modo de proceder teórico obriga-nos a desenvolver uma análise ao redor de certas intuições sobre o presente e encaminha a marca substancial que a imagem impõe ao pensamento contemporâneo. Certas proposições da reflexão filosófica procuram estruturar novos modos de se enfrentar ao presente e ao pensamento. Saber quais são as mutações do pensamento e como a invasão de imagens gera novas transformações estabelece um modo de aceso ao nodamento entre tempo e imagens desde uma perspectiva que contempla a supervivência dos restos materiais da história como motor de atualização do tempo. Assim, esta aproximação, em contraponto com os procedimentos compositivos da arte contemporânea - e mais especificamente da literatura contemporânea - nos permitirá explorar as possibilidades de articulação entre os elementos antes mencionados sob a lógica da montagem. Com esse objetivo, esta reflexão estará acompanhada com imagens textuais extraídas do Informe sobre ectoplasma animal (2014) de Roque Larraquy e Diego Ontivero.
\end{abstract}

Palavras-chave: montagem; imagem; literatura.

\section{Resumen}

Preguntarnos por el presente objetivando el tiempo en un corte que coincide con nosotros mismos resulta casi irrealizable. Sólo podemos confiar en vislumbrar ciertas grietas o pasajes que fracturan el propio presente para, a partir de allí, arriesgar algún tipo de articulación. Pensar en imágenes como modo de proceder teórico nos obliga a desarrollar un análisis alrededor de ciertas intuiciones sobre el presente y remite a la marca sustancial que la imagen impone al pensamiento contemporáneo. Ciertas proposiciones de la reflexión filosófica buscan estructurar nuevos modos de enfrentarse al presente y al pensamiento. Saber cuáles son las mutaciones del pensamiento y cómo la invasión de imágenes genera nuevas transformaciones establece un modo de acceso al anudamiento entre tiempo e imagen desde una perspectiva que contempla la supervivencia de los restos materiales de la historia como motor de actualización del tiempo. Así, este acercamiento, en contrapunto con los procedimientos compositivos del arte contemporáneo - y más específicamente de la literatura contemporánea -, nos permitirá explorar las posibilidades de articulación entre los elementos antes mencionados bajo la lógica del montaje. Con ese objetivo, esta reflexión estará acompañada con imágenes textuales extraídas del Informe sobre ectoplasma animal (2014) de Roque Larraquy y Diego Ontivero.

Palabras clave: montaje; imagen; literatura. 
1. Debemos considerar aquellos regímenes de visibilidad que entran en diálogo. Considerar, entonces, desde la perspectiva benjaminiana, el procedimiento alegórico como marco de inteligibilidad. Estas consideraciones, sobre las que volveremos más adelante, son el centro de la problemática del estudio sobre la calavera como alegoría barroca que lleva adelante W. Benjamin en su Ensayo sobre el origen del drama barroco alemán. (En español: BENJAMIN, Walter. El origen del drama barroco alemán, 1990.) y serán fundamentales para articular el despliegue de los términos de la legibilidad de la imagen.

2. Alrededor de estos términos trabaja DIDI-HUBERMAN, Georges. Cuando las imágenes toman posición, 2008, p. 118.

3. Tomamos la expresión de Peter Bürger y compartimos el recorte espacio-temporal que propone el autor: "El concepto de movimientos históricos de vanguardia que se aplica en este libro al dadaísmo y al primer surrealismo también se refiere a la vanguardia rusa tras la Revolución de Octubre. Estos movimientos tienen en común, aunque difieren en ciertos aspectos, que no se oponen a determinado procedimiento artístico, sino al arte en general, es decir, generan una ruptura con la tradición.

Sus manifestaciones se dirigen contra la institución arte. [...] con sus limitaciones esto también vale para el futurismo italiano y el expresionismo alemán. El cubismo [...] sí cuestionó el sistema de representación vigente desde el Renacimiento, el cual se basaba en la perspectiva central. Puede incluirse como vanguardia, aunque dentro de sus fundamentos no se encontraba
Podemos comenzar por preguntarnos ¿qué muestra el montaje? ¿Cómo? Pero, además, ¿qué condiciones de visibilidad/legibilidad trae aparejadas? ${ }^{1}$ Reteniendo estas interrogaciones en suspenso podemos desviarnos hacia otra de las implicancias fundamentales de la cuestión: el modo en el que, en tanto procedimiento, el montaje se relaciona con el trabajo dialéctico como motor de su hacer. Resulta significativo determinar el protagonismo de este despliegue bipolar. Por un lado, la determinación histórica: el evidente desencadenamiento contextual que atañe a las lógicas del devenir. Por el otro, la excepción: el inesperado revés que desafía la estructura y revela sus márgenes. Considerar esta tensión al interior del mecanismo es tarea fundamental al momento de abordar la técnica de montaje como principio compositivo, así como también necesario para intentar pensar al montaje como modo de conocer. Flujo o discontinuidad, forma o deformación ${ }^{2}$, en la tensión de ese entre se encuentra la clave.

Considerar al montaje como procedimiento artístico implica, a la vez, considerar el momento en el que el arte comienza a multiplicar posibilidades. La íntima relación entre el surgimiento de los nuevos desarrollos técnicos y la disponibilidad universal $\beta$ de los medios artísticos desde comienzos del siglo XX produce una modificación medular en la reflexión del arte sobre sí mismo. De este modo, los medios cobran central relevancia en el proceso compositivo y el arte adquiere una praxis de experimentación transgresora. Así, arte y técnica alcanzan una dinámica que, brevemente, podría describirse como un intercambio ligado a la creación de novedad que sólo puede ser posible en la manipulación de los recursos disponibles. La demanda del arte sólo se libera a través de la técnica ${ }^{4}$. Este es el viraje central que produce la vanguardia en su intento de devolver el arte a la praxis cotidiana: la búsqueda de integración de lo real-histórico en los objetos del arte. La intencionalidad de la producción se dirige a destruir el concepto clásico de duplicación de la realidad (propio del realismo) para dar lugar a la materialidad objetual como realidad en sí misma. Desde la vanguardia los objetos artísticos pierden referencialidad aun cuando poseen una intención mimética (por ejemplo en el hiperrealismo). El cuestionamiento hacia "lo real" se encuentra inscripto en la misma obra.

Si además nos guiamos por la premisa brechtiana que sugiere que toda forma estética se encuentra asociada a un contenido ético - premisa que se hace posible, como decíamos, a partir del cambio de percepción que resulta del intento del arte de abandonar el "reflejo" de la realidad - la modificación que propone la vanguardia es la de presentar a través del ingreso de la dimensión material en la composición una toma de posición respecto del trabajo que subyace al interior de los 
aparatos estéticos. El montaje, en estos términos, se propone como un modo de exposición que altera las relaciones previas de lo ya dado para exponer la dimensión problemática de una interacción. Trabaja sobre la fugacidad del intervalo que se abre en el instante de aparición de la imagen. No se propone como la suma de los elementos sino que el resultado de esta operación es siempre supra-numerario. Ese plus no estaría derivado de algún más allá de esos materiales concretos sino que el procedimiento mismo opera en las grietas que se abren allí donde se superponen los elementos. Montaje no es simple yuxtaposición, suma o enfrentamiento. Por ese motivo su carácter de continua creación de significados. Parte de la importancia de lo singular como principio heurístico y, a partir de allí, proyecta sus consideraciones sobre la historia y el arte. El montaje fuerza a franquear las barreras que, intencionalmente ${ }^{5}$, separan lo uno de lo distinto, y del mismo modo fuerza las potencialidades intrínsecas de los elementos que expone. Además convoca, por su anacronismo constitutivo, temporalidades múltiples para que actúen sobre lo presente. Su particular modo de cita hace permanecer en cada fragmento su valor singular - con las latencias que acarrean de su primer contexto - para luego superponer dichas singularidades en una puesta en relación que tensiona con lo descontextualizado ( $\mathrm{y}$ con su posterior re-configuración). El montaje batalla por la articulación de los elementos que es, a la vez, una batalla por "recomponer las fuerzas y los terrenos de producción. Por ejemplo el de la imagen frente al texto"

Decimos, entonces, que la proposición del montaje se deja ver en su totalidad cuando estallan los significados tejidos hacia el interior de cada fragmento. Este choque, confluencia de materia y tiempo, destruye lo previo para generar una nueva configuración sólida. Configuración en la que, sin embargo resuenan fantasmas de tiempo pasado. Esta intermitencia, en tanto potencia constructiva, es la que verdaderamente trae la imagen definitiva (aunque siempre cambiante) de la urdimbre que trabaja hacia el interior de la composición. Así, los elementos nunca están en reposo, y es en esa vibración constitutiva donde se aloja la productividad del montaje en tanto técnica.

La discontinuidad es la cualidad diferenciada de articulación entre los elementos ensamblados. Ante el ojo del montajista cualquier fenómeno se presenta como una secuencia estructurada de singularidades superpuestas. Así, para la concepción benjaminiana de la historia, la solidez de las estructuras que intentan darse a ver como totalidad, se halla siempre fisurada desde los lugares tangenciales ${ }^{7}$. En este sentido, un análisis materialista de la historia parte de una especial atención a la distribución de los acontecimientos a partir de sus posiciones respectivas. Todos los elementos adquieren su la tendencia de las vanguardias, aquella relacionada con la superación del arte en la praxis cotidiana." BÜRGER, Peter.

Teoría de la vanguardia, 2010, p. $26 ; 24$.

4. Esta idea puede ser rastreada en Peter Bürguer. Ibidem, p. 41 42. Las páginas pertenecientes al subcapítulo llamado "Benjamin y la discusión en torno a una teoría del arte" manifiestan un conflicto en torno al corte benjaminiano entre arte aurático y arte no-aurático. Aun coincidiendo con las tesis centrales del trabajo del autor, aquí se advierte una carencia en cuanto a una posición antagónica consistente. Sumado a esto, la crítica de Bürger concluye en que la lectura de W. Benjamin resulta más cercana en su objeto a la fotografía y al cine (en tanto representantes de los nuevos medios técnicos) y parece dejar de lado temas de suma complejidad en la obra de Benjamin que justifican la centralidad de la palabra en el debate sobre el arte. Tales serían, entre otros, el escollo que propone la noción de imagen dialéctica y el trabajo de escritura del propio autor. Nos resulta desacertado, por tanto, el argumento que sugiere que el trabajo benjaminiano sobre la técnica procedimental no alcanza a la literatura del mismo modo que a otras esferas del arte.

\section{Decimos intencionalmente en} tanto no puede pensarse la separación de las esferas de lo político y lo estético sino como corte arbitrario. Esta es la condición a partir de la cual se juzga a la estética realista como estilo neutralizador de los conflictos latentes en "lo real". Las estéticas realistas (en la pretensión de des-marcar las producciones) insisten en posicionarse como copia fiel de una realidad (supuestamente) dada. De este modo ocultan 
las posiciones subjetivas que determinan el acceso a "lo real" ("Cuando en el arte leemos [...] sin partido significa que pertenece al partido dominante" -B. Brecht, apud. DIDI-

HUBERMAN, Georges. Cuando las imágenes toman posición, 2008, p. 129).

6. Ibidem, p. 146.

7. Recordemos que la frase que Walter Benjamin toma de Aby Warburg: Der liebe Gott steckt im Detail, define una relación con el material histórico al tiempo que un modo oblicuo de acercarse a los fenómenos.

8. Importamos este concepto de los estudios de Florencia Garramuño (2015) sobre los entrecruzamientos en el arte contemporáneo.

9. DIDI-HUBERMAN, Georges. Cuando las imágenes toman posición, 2008, p. 170. importancia decisiva en relación con la composición. Lógica que a su vez puede observarse hacia el interior de los mismos objetos del arte en un juego que recuerda al que proponen las muñecas rusas. Las significaciones, entonces, se construirán con arreglo al estado de tensión que se encuentren, según la posición estructural de los elementos. De ahí que aquellas no puedan separarse de una consideración de las temporalidades que colisionan ante la vista del observador.

Del montaje se puede decir que es constructor de nuevas significaciones, tanto como que su clave visual se juega en la continua disociación de los elementos. La mirada del montajista está siempre atenta a cada parte, a la singularidad de los fragmentos que organizan una compleción siempre inacabada. Su carácter no resuelto le permite renovarse a sí mismo. Siempre resta un plus de sentido que no cesa de ser reapropiado por nuevas y más complejas interpretaciones. Esta condición fundamental es la que asegura la productividad del retorno de lo que nunca resulta idéntico a sí mismo. Eso que resta y que no puede ser apropiado es su mismo centro que se desplaza continuamente y que no permite ser mirado a la cara más que en un instante de fulguración. Así, el trabajo con el fragmento tiene una doble capacidad: por un lado hacer visibles las fracturas constitutivas, por el otro, organizar nuevos modos de la percepción. La acción del fragmento colisiona con el pensamiento unilateral que busca la reducción hacia el concepto, subraya las rupturas y los espacios evidenciando que, en los intersticios de las estructuras, hay partículas que no pueden ser reducidas a una coherencia totalizadora. De allí la incomodidad de la interacción entre las partes. Es por ese motivo que el montaje en cuanto técnica compositiva permite alojar diferentes materiales permitiendo el entrecruzamiento no sólo de diversos registros sino también de diversos soportes. En términos hubermanianos: interposiciones, o, para acercarlo a un análisis estético contemporáneo, la inespecificidad ${ }^{\beta}$ característica del arte del presente. El cruce de los campos artísticos hace de sus objetos artefactos complejos que continúan socavando los presupuestos del arte como esfera diferenciada. Así lo dice Adorno, en el L'art et les arts, citado por Didi-Huberman:

[...] Es como si los géneros artísticos, al negar los contornos firmes de su figura, royeran el concepto mismo de arte. El fenómeno originario del deshilachamiento del arte lo encontramos en el principio del montaje que se impuso antes de la Primera Guerra Mundial con la explosión cubista?.

El escenario que se plantea por la interacción que determina el trabajo con fragmentos es el de un despliegue en el que los resultados son momentos provisionales en un punto determinado de un proceso. Quiero decir, cada montaje 
puede considerarse el punto exacto de un equilibrio que siempre se encuentra en riesgo. Si la unidad elemental de estas composiciones es una unidad fragmentada no puede menos que permanecer esa intención destotalizante en los artefactos que configura. Así, los artefactos estéticos marcados por este modo de construcción cristalizan en un instante de una trama que los precede y también los sucede. El punto exacto del darse a ver coincide con una encrucijada espacio-temporal que no cesa de reconfigurarse cada vez que se replantean las bases sobre las que reposa. Un simple cambio de espacio, un breve intervalo temporal puede significarle a ese objeto una total modificación interpretativa.

Para desplegar un análisis sobre la trayectoria de la técnica de montaje - propuesta aquí en relación al corte estético-político impuesto por las vanguardias históricas al arte moderno - nos resulta indispensable, además, considerar la inseparable relación que se establece entre montaje y alegoría. Como señala Luis García, alegoría y montaje coinciden en el origen: "parten de una sustracción que les es constitutiva (no hay la imagen del horror sino siempre trozos, astillas)" ${ }^{\prime 10}$. Los detritus de la historia son la materia de base para ambos procedimientos de representación, a la vez que hay una pérdida que no cesa de manifestarse en los intersticios de lo expuesto. La diferencia fundamental radica en el carácter de cada procedimiento. La alegoría barroca es marcadamente melancólica en su modo de aproximación a la ruina ${ }^{11}$, mientras que el montaje - cuyas ruinas son las de un derrumbamiento signado por la cercanía de las Guerras Mundiales - es fundamentalmente constructor. Asociado a la figura del ingeniero - en la estela benjaminiana ${ }^{12}$ - no puede escapar a la impronta de la acción por su íntima relación con los modos de trabajo de la vanguardia.

Si comprendemos la clave dada por el vínculoentre visibilidad y legibilidad podemos leer la interrupción de una comprensión teleológica y la consecuente visión no-trascendental de la historia. Esta perspectiva es la que permite otorgar centralidad a la figura de la calavera en los estudios de Walter Benjamin. Dicha figura trae aparejadas una serie de conclusiones que resultan de vital importancia para la comprensión de la alegoría como eslabón inmediatamente anterior al surgimiento del montaje en tanto principio constructivo de la modernidad estética: a) la alegoría pone en cuestión el carácter intemporal de la imagen, devuelve la imagen a su pertenencia histórica (y el conflicto de temporalidades impuras que se alojan hacia el interior de sus figuras), b) la alegoría pone en crisis el concepto de imagen como vehículo de un significado unívoco (disuelve la voluntad totalizante), c) la alegoría, en tanto determinada por la historia, permite acceder a una lógica de la imagen a partir de la cual es posible estudiar el presente. Se hace posible, entonces, pensar
10. GARCÍA, Luis. "Alegoría y montaje. El trabajo del fragmento en Walter Benjamin”. Constelaciones, 2010, p. 160.

11. Para situar la cercanía del trabajo alegórico en función de la ruina, en relación al estudio benjaminiano del universo de Baudelaire: "Lo tocado por la intención alegórica quedará apartado del contexto de la vida: destruido y conservado al mismo tiempo. La alegoría se aferra a las ruinas. Ofrece la imagen de la agitación petrificada. El impulso destructivo de Baudelaire no está interesado nunca en la abolición de aquello que está a su merced". BENJAMIN, Walter. El París de Baudelaire, 2012, p. 56.

\section{Consecuente a la} intervención de la figura del ingeniero en la esfera del arte, la arquitectura y el diseño desde finales del s. XIX, se encuentra la dedicatoria de W. Benjamin a Asja Lacis en Calle de dirección única: "ESTA CALLE SE LLAMA / CALLE ASJA LACIS/ NOMBRE DE AQUELLA QUE/ COMO

INGENIERO/ LA ABRIÓ

EN EL AUTOR”. Ídem. Calle de dirección única, 1987, p. 13. 
13. DIDI-HUBERMAN, Georges. Cuando las imágenes toman posición, 2008, p. 189.

14. Sobre las constelaciones, en palabras del propio Benjamin:

"Las ideas son a las cosas lo que las constelaciones son a los planetas. Esto primero quiere decir esto: no son ni su concepto ni la ley." Apud. DIDI-HUBERMAN, Georges, ibidem, p. 154.

15. Cf. BENJAMIN, Walter. "Apartado J [Baudelaire]", 2005, p. 247-392. que si la ruina funciona como escenario de despliegue de la figura de la calavera en tanto alegoría del habitar barroco del mundo y, en este escenario, la imagen se transforma en la unidad clave de sentido donde condensa el sentido de la historia, esa relación que se establece entre tiempo de la ruina y representación es análoga a la reapropiación del derrumbamiento de la historia (en tiempos de la vanguardia) y el montaje en tanto técnica compositiva. La alegoría es comprendida como el recurso primero que "reconduce la interrupción del continuum cronológico a nivel espacial: trocea la naturaleza exponiendo objetos parciales"13, procedimiento que será retomado el montaje para construir a partir del fragmento. Dicha técnica también recuperará los restos arqueológicos que retornan como síntomas de la historia para ser reconfigurados en una lógica espacial (en tanto objetos físicos) pero sin omitir que contienen, además, la latencia de un conflicto de temporalidades.

Asimismo, la alegoría es un punto de anclaje desde donde podemos comenzar a reflexionar el vínculo entre imagen y escritura. Si, como decíamos anteriormente, el procedimiento alegórico revoca la univocidad de la relación entre imagen y sentido (propia del mecanismo simbólico) es porque no resuelve las tensiones internas de dicha co-pertenencia. La imagen alegórica plantea una demanda de ser leída pero esa lectura requiere un análisis diferenciado de diversos conflictos que se alojan allí. Más precisamente, requiere un trabajo dialéctico de varios niveles en simultáneo. Las tensiones hacia el interior de la imagen son tensiones inquietas que rechazan los intentos de correspondencias directas. Entonces, es este carácter de lo despedazado, de lo jeroglifico lo que empuja de la imagen hacia la escritura. Y viceversa: la escritura que pretende hacer eco de las correspondencias internas que se ajustan a sentidos despedazados y que, sin embargo, conforman una constelación de ideas semejantes ${ }^{14}$, culminan por condensar en una imagen. Es por estos motivos que la legibilidad de la alegoría se acerca a la del montaje, ya que, para ser leídas, es indispensable proceder desde la consideración del carácter del fragmento. La imagen que se asocia en Benjamin es la de puz:le $e^{15}$ para decir que el encastre provisorio de las piezas depende tanto de los cortes, cuanto de los contornos, a la vez que la conformación de la estructura responde a la yuxtaposición de unas singularidades de contenido propio pero que sólo terminan de darse a ver en la lógica de conjunto. La alegoría devuelve al hombre - pensando ya, después del estudio sobre el drama barroco, en el hombre moderno encarnado en la figura de Baudelaire - la apuesta por la consistencia del sentido en un mundo dominado por la inconsistencia y la disolución. La diferencia radical con el montaje es consecuencia propia del quiebre técnico que ocasionan los nuevos medios de 
reproducción que de a poco ingresan al mundo del arte y los medios masivos de comunicación. La sintaxis específica de la era de la reproductibilidad técnica se encuentra marcada por una nueva experiencia de la vida urbana y una nueva relación con los materiales de trabajo del artista (ahora más asociado a la figura del constructor que a la del creador). Si la disolución del sentido tendía a un despliegue visual ya en el caso de la alegoría, el montaje extrema este funcionamiento para enfrentarse a los dispositivos totalizantes y su visión de la historia, de la política y de la verdad. Los modos de yuxtaposición que resultan de la experimentación con la técnica logran interrumpir la tranquilidad del discurrir histórico (en cada montaje habitan temporalidades múltiples) así como recupera la imagen resultante ya no como re-presentación de una escena exterior al arte sino como imagen visual que reivindica su carácter de artificio. La interrupción, entonces, se manifiesta como el intervalo que hace posible dar visibilidad a los conflictos latentes en la dinámica del montaje. Tanto la disolución del sentido que busca trasladarse hacia lo visual, cuanto la interrupción como espacio necesario para que destelle - por lo menos por un instante - la suma de las complejidades constitutivas de la estructura, resultan elementos centrales al momento de considerar la técnica de montaje como principio constructivo. En palabras de Luis García, al referirse al montaje filosófico benjaminiano:

[...] en el montaje histórico benjaminiano se desconecta el acontecimiento particular a un sentido trascendente (se desaloja toda teodicea), y la empatía con el vencedor es desplazada por la interrupción del continum de la historia. Crítica del 'progreso' y recuperación de la 'imagen', del carácter plástico o visual (bildlich) del saber, son una y la misma cosa: para conceptualizar la interrupción del continuum histórico en un súbito lazo del presente con su pasado se precisa de una imagen que vehiculice la condensación de presente y pasado. ${ }^{16}$

De este modo, intentamos articular el espesor de una consideración visual que se despliega en términos espaciales junto a la capacidad disruptiva de la imagen fragmentada. Cuando de la historia retenemos las imágenes, la clave se posiciona en las tensiones de la estructura.

\section{Del montaje en literatura}

El conocimiento por montaje ${ }^{17}$ trabaja a partir de una dialéctica de la imagen en tanto torbellino de sentidos, lugar de centelleo de ideas; y conserva, por propiedad intrínseca de la técnica,
16. GARCÍA, Luis. "Alegoría y montaje. El trabajo del fragmento en Walter Benjamin". Constelaciones, 2010, p. 179.

17. DIDI-HUBERMAN, Georges. Ante el tiempo. Historia del arte y anacronismo de las imágenes, 2011, p. 174. 
18. LARRAQUY, Roque; ONTIVERO, Diego. Informe sobre ectoplasma animal, 2014. dichas particularidades al interior de los objetos que genera. Trae aparejada una apuesta constructiva que evade las concepciones totalizantes de la significación y se resiste a la unicidad de sentidos. El trabajo material con privilegio del significante, que yuxtapone hasta más no poder, es un trabajo que busca en los modos de representación vías de acceso a un tipo de conocimiento (muchas veces imperfecto, siempre incompleto, pero que no abandona el trabajo crítico). Es un modo de proceder que privilegia la multiplicación en lugar de la definición estable y que no depone su capacidad pensante al mismo tiempo que continúa creando. Por tanto, cuando de la literatura se trata, el trabajo de montaje es un trabajo con el lenguaje que se ubica frente a sí mismo generando disputas de sentido. Mediante esta lógica, la yuxtaposición deja a la vista las relaciones trazadas entre los elementos. Lo central son estas relaciones. El movimiento es lo imprescindible al montaje como técnica compositiva. En el espacio textual los elementos nunca están quietos y continuamente amenazan con disparar nuevos sentidos, con amalgamarse de diferentes modos e incluso con perderse en la incomprensión por su complejidad constitutiva. Esas tensiones son las que se resuelven en la operación de lectura. En tanto composición, la del montaje es una función desterritorializante que insiste con el trabajo del recuerdo y con los restos que sobreviven al tiempo. Un juego infinito de gran potencia experimental que descubre que lo central es el mecanismo, que la técnica coincide con los modos de pensar.

Quisiéramos poder pensar estas cuestiones trayendo una producción concreta de reciente publicación como exemplum de las tensiones que apareja el uso del montaje como técnica compositiva en literatura. Buscando en los márgenes de la literatura, en lo que se desajusta de un recorrido marcado previamente por el canon, lo que aquí se juega es un ejercicio problemático de contacto con una propuesta de despliegue espacial hacia adentro del artefacto literario. En el Informe sobre ectoplasma animal ${ }^{18}$ (a partir de aquí: IEA) se juega un continuo interrumpirse del texto (Roque Larraquy) por la insistencia de las ilustraciones (Diego Ontivero) que suspenden el recorrido lineal. De este modo, la fuerza disruptiva radica en su capacidad de suspensión y fijación que, al detener el flujo del texto, condensa los trayectos y asocia palabras y formas. Deberíamos preguntarnos: ¿qué hay en el diseño industrial - en el soporte de vectorizado en $2 \mathrm{D}$, en los colores o su ausencia, en el espacio que despliega - que permite la escritura? ¿Qué es aquello que soporta las latencias que pasan del texto a la ilustración? ¿Cuál es ese pasaje?

Esta relación compleja, que no permite reducir a un carácter meramente ilustrativo a la imagen gráfica respecto del texto, es la que lleva adelante la progresión del relato siendo 
cada registro por sí mismo incapaz de igualar la potencia que se da en la yuxtaposición. Por una parte, las ilustraciones que propone Ontivero - imágenes provenientes del registro del diseño gráfico - presentan una serie de volúmenes sin registro de escala que funcionan como planos de una doble valencia. Las ilustraciones no vienen a representar al texto pero guardan una estrecha vinculación con lo que la palabra propone: su vacío se llena - de la misma manera que se llenan los shifters en el análisis greimassiano - por desplazamiento. En este sentido es que podemos afirmar que las imágenes se sostienen por sí mismas, esto es, que no re-presentan (no están en lugar de otra cosa) sino que su complejidad radica en el juego dialéctico de ambos registros. En contrapartida, las palabras construyen a partir de la lógica del fragmento y por su vinculación con las imágenes que las rodean. Para pensar esta lógica de reenvíos, que, como ya dijimos, sólo es posible a partir de pensar esta imbricación en términos de montaje, necesitaremos conectar el espacio textual con el espacio de la imagen gráfica a partir de un modo que los implique mutuamente. El término técnico que encontramos para nombrarlo es el de materia fluida ${ }^{19}$ que permite reconocer una transcripción mutua, en la clave correspondiente a cada registro, desde el texto hacia la imagen gráfica y viceversa. Término que permite considerar también la dimensión material de la cuestión y los modos en que, por esta causa, hay una acumulación en la que todo lo involucrado en este diálogo de lógicas diversas adquiere carácter por lo que lo precede y por aquello que le sigue. Cabe destacar que, en el análisis que llevaremos adelante, se comprende que el IE $A$ es un objeto que genera imágenes a la vez que trabaja con otras previas, y toda su lógica compositiva es una maqueta de aquello que busca traer a la vista. Consideramos, así, que aquello que se trabaja en términos de los fragmentos que componen el texto, como cada una de las imágenes ya sean gráficas o textuales, trabajan del mismo modo que la estructura macro del artificio textual. A partir de esta consideración es que deberán ser atendidos los ejemplos que extraemos a continuación.

De las imágenes textuales llama poderosamente la atención la que responde al nombre de enjambres. Relata en una carta el personaje Severo Solpe, presidente de la Sociedad Ectográfica Argentina: "[...] llamo enjambre a una técnica todavía tosca de unión entre espectros o fragmentos de espectros, con los que producimos ectoplasma intervenido" ${ }^{20}$ y más adelante: "Olvidarse de la biología y hacer enjambres más osados fue idea de Julio, que produjo un ectoplasma compuesto por materia de varios animales distintos, de interpenetración inestable, difícil de mantener en su sitio pero exquisito a la vista. También lo perdimos." ${ }^{21}$ La entrada ENJAMBRE del Informe de Ectoplasma Animal corresponde al VIERNES 5 DE SEPTIEMBRE DE
19. ORTIZ, Mario.

"Conferencia abierta". Cantos de experiencia vol. II, 2015.

20. LARRAQUY, Roque; ONTIVERO, Diego. Informe sobre ectoplasma animal, 2014, p. 71.

21. Ibidem, p. 73. 
22. Ibidem, p. 62

23. Ibidem, p. 79.

24. Ibidem, p. 78.
1930, un día antes de que estallara el primer golpe de estado del siglo XX en Argentina. Las cartas, de las que sólo se transcriben fragmentos, se dirigen a "Eugenio Dubarry, senador nacional por la Ciudad de Buenos Aires"22 cuyo objetivo principal parece ser el de conseguir apoyo por parte del Estado para la investigación en materia de ectoplasmas y la defensa del edificio donde se desarrollan las actividades. Solpe justifica su pedido argumentando que los resultados de las investigaciones se dirigen, en gran parte, a contribuir con las Fuerzas Armadas desarrollando enjambres como posibles "herramienta[s] ofensiva[s] para regulación y control de asuntos nacionales" ${ }^{23}$. El plano de la ficción se anuda con la historia política.

El desmontaje de la historia en las líneas que la conforman permite conocer el entramado que sostiene a la historia como discurso, al tiempo que devuelve a cada parte su valor compositivo. Montaje significa: disección, manipulación, reposicionamiento. Los cortes y las nuevas correspondencias que convoca dejan entrever lo ilusorio de las verdades que se procuran indiscutibles. La historia disgregada en imágenes y las imágenes descompuestas en sus partes elementales inauguran el juego de la fractura abierta que reclama su darse a ver y construye a partir del fragmento. En tanto montaje de la experiencia colectiva Nacional, el enjambre, en su relación con la política Argentina, se vuelve cuerpo-figura de los procesos de conformación identitarios e intervienen en los discursos dominantes atentando contra el saber institucionalizado:

Al mediodía / eran las tres de la tarde/ el enjambre desplegó una pata articulada y practicó movimientos rápidos sobre el cielo de la avenida [9 de Julio] como tanteando un posible sostén. La apoyó en la cabeza de un hombre que celebraba con otros en un balcón un piso más abajo. El hombre sacó un arma y disparó varias veces al aire. / Lo bizo directamente sobre la gente de la avenida, sin acertarle a nadie. / Le respondieron otros disparos anónimos de festejo. Mientras estuvo en contacto con el enjambre gritó y maldijo más que todos sus compañeros de balcón, hasta que alguien los invitó adentro para un brindis y el hombre giró y tropezó con otro, desligándose. Esto produjo un curioso efecto elástico de retracción en el cuerpo del enjambre y lo hizo caer sobre la muchedumbre de la avenida, donde se perdió [...]. Se impone investigar estos efectos del enjambre en la conducta, sus alcances y el modo de destinarlos a un fin. ${ }^{24}$

Además, con suficiente atención, podemos distinguir en este último párrafo los cortes de un montaje de diferentes registros de texto. Lo que se encuentra entre barras es la marca de la inscripción del notario que transcribe lo que el personaje S. Solpe le dicta. Esa notación intercalada responde al mismo modo de introducir el enfrentamiento de posiciones en el 
registro discursivo tanto a nivel de contenido como por la marcada diferencia de estilo tipográfica.

A su vez, el texto se articula con ilustraciones en blanco y negro. En este punto se abandonan las líneas curvas que dinamizaban las ilustraciones bidimensionales del comienzo para dar lugar a la dominancia de paralelas diagonales que generan otros recorridos de la mirada. Por superposición de planos se logra instalar la relación de profundidad por el juego de luces y sombras. Todos estos elementos se asocian y fluctúan y lo que se ve es siempre ya remisión hacia alguna dimensión del enjambre producido por imagen, texto y temporalidad. Cada estrato diferenciado se comporta en consonancia con la estructura de una maqueta mayor. El montaje es tanto de imagen y de texto, cuanto montaje dentro del registro textual, así como también la superposición de planos genera la imagen gráfica por montaje. Cada parte remite a un espacio más macro. En cada nivel se enfrentan diferentes elementos y, a su vez, cada nivel se enfrenta a otros a partir de las propias diferencias. De ese modo la composición está en tensión constante. El juego de yuxtaposiciones deja verse desde las partículas más elementales y esa estrategia se extiende hacia toda la estructura. De esto se deriva un modo de producción. Su base se articula a partir de una lógica de reminiscencias que no cesa de construir sentidos. Las posiciones subjetivas recuperan un espacio central tanto para la configuración de estas insistencias como para su decodificación. Su legibilidad se encuentra condicionada por cierta capacidad de leer aquello que no está escrito.

En la suma compleja que se produce por yuxtaposición de elementos, las relaciones que tensionan son relaciones noevidentes. Los trazos que unen los puntos fuertes del relato se construyen en una paralela desplazada del sentido lineal. Todo allí se encuentra sobredeterminado. Es así que la vía de conocimiento que inaugura el montaje se encuentra en consonancia con aquellas heterotopías que insisten con deslizarse de las direcciones marcadas para reconfigurar el presente de su aparición. Si pudiéramos asociar esto con las reflexiones que, a partir del pensamiento de Vilém Flusser, marcan un continuo en el pensamiento por una nueva onto-imaginiería ${ }^{25}$ - que se encuentra pensando al mismo tiempo en que se renuevan las técnicas de producción de las imágenes -, tal vez podríamos asociar los modos propios del funcionamiento de las lógicas compositivas que batallan en mundo del arte actual. El montaje es uno de ellos, nombre con el que, genéricamente, se pretende reunir aquellas capas arqueológicas que dan origen a un presente que aún no se hace efectivo.

Un pensamiento crítico que apunte a desmontar los aparatos estéticos contemporáneos en perspectiva diacrónica se convierte, al instante, en un modo de acercar las consideraciones
25. Claudia Kozak, apud. FLUSSER, Vilém. El universo de las imágenes técnicas. Elogio de la superficialidad, 2015, p. 15. 
estéticas y políticas que caben dentro del pensamiento sobre el arte. Sólo desde allí se hará posible arriesgar ciertas combinaciones teóricas que se encuentren a la altura de un análisis del presente que nos interpela.

\section{Referencias}

BENJAMIN, Walter. Calle de dirección única. Madrid: Alfaguara, 1987.

. Discursos interrumpidos I. Madrid: Taurus, 1987.

. El libro de los pasajes. Madrid: Akal, 2005.

_. El París de Baudelaire. Buenos Aires: Eterna Cadencia, 2012.

BUCK-MORSS, Susan. Dialéctica de la mirada. Walter Benjamin y el proyecto de los pasajes. Madrid: Antonio Machado, 1989.

BÜRGER, Peter. Teoría de la vanguardia. Córdoba: Las cuarenta, 2010.

DIDI-HUBERMAN, Georges. Ante el tiempo. Historia del arte y anacronismo de las imágenes. Buenos Aires: Adriana Hidalgo, 2011.

Cuando las imágenes toman posición. Madrid: Antonio

Machado, 2008.

FLUSSER, Vilém. El universo de las imágenes técnicas. Elogio de la superficialidad. Introducción y notas por Claudia Kozak. Buenos Aires: Caja Negra Editora, 2015.

GALENDE, Federico. Modos de producción. Notas sobre arte y trabajo. Santiago de Chile: Palinodia, 2011.

GARCÍA, Luis. "Alegoría y montaje. El trabajo del fragmento en Walter Benjamin", Constelaciones. Revista de teoría y crítica. n. 2, p. $158-185$, dic. 2010.

GARRAMUÑO, Florencia. Mundos en común. Ensayos sobre la inespecificidad en el arte. Buenos Aires: Fondo de Cultura Económica, 2015.

LARRAQUY, Roque; ONTIVERO Diego. Informe sobre ectoplasma animal. Buenos Aires: Eterna Cadencia, 2014. 